\title{
Dimorphism in males of Zaops ostreum (Say) (Crustacea, Decapoda, Pinnotheridae)
}

\section{Cheruparambil Sankarankutty ${ }^{1}$ \\ Alexander C. Ferreira ${ }^{1}$}

\begin{abstract}
A case of dimorphism among the males of the pinnotherid crab, Zaops ostreum (Say, 1817), is reported. The morphological features of the two types of males are also given.

KEY WORDS. Zaops ostreum, dimorphism, males
\end{abstract}

A study being carried out to determine the diversity of carcinofauna of the estuaries of the State of Rio Grande do Norte has recorded Zaops ostreum (Say, 1817) associated with the oyster Crassostrea rhizophorae in the estuary near Macau, Rio Grande do Norte, Brazil. Though C. rhizophora is not uncommon in the other estuaries under investigation, the presence of $Z$. ostreum has not been recorded so far.

Though sexual dimorphism is a common phenomenon among the pinnotherid crabs necessitating separate keys for males and females for the identification of the species (RATHBUN 1918; Williams 1984; MANNING 1993), the existence of two types of males within the same population is not common.

Of the four estuaries under investigation (Macau, Galinhos, Potengi and Guaraira), the oysters attached to the mangrove vegetation are common in the first three of them. However, the material for this report was obtained only from the estuary of Macau - a total of 39 females and 26 males. The table I shows how they were distributed within the oysters.

Table I. Distribution of Zaops ostreum within the oysters.

\begin{tabular}{|c|c|c|c|c|c|c|}
\hline \multirow{2}{*}{ Dates of collection } & \multicolumn{2}{|c|}{ Single occupancy } & \multicolumn{2}{|c|}{ Double occupancy } & \multicolumn{2}{|c|}{ Triple occupancy } \\
\hline & Female & Male & Femlae & Male & Female & Male \\
\hline July 1996 & 2 & - & 3 & 3 & - & - \\
\hline September 1996 & 3 & 2 & - & - & - & - \\
\hline December 1996 & 4 & 1 & - & - & - & - \\
\hline January 1997 & 8 & 4 & 3 & 3 & - & - \\
\hline March 1997 & 6 & 1 & 3 & 3 & - & - \\
\hline April 1997 & 1 & 2 & 3 & 3 & 1 & 2 \\
\hline
\end{tabular}

A detailed examination of the males revealed the existence of two distinct types of males (Fig. 1) within the same population. The principal differences are in the shape of the carapace, the shape of the frontal lobe and the shape and size of the

1) Departamento de Oceanografia e Limnologia, Universidade Federal do Rio Grande do Norte. 59014-100, Natal, Rio Grande do Norte, Brasil. E-mail: sankaran@ digi.com.br 
propodus of the walking legs. Type A (Fig. 1A) has globose and soft carapace with the frontal margin a little concave and the propodus of the walking legs narrow and deprived of long setae. Type B (Fig. 1B) has a flattened and hardened carapace, having a distinctly bilobed front, broadened propodus of walking leg with a distinct longitudinal row of long setae - a characteristic feature of $Z$. ostreum. While type A is more common (58\%), type B represents $42 \%$ of males collected. Only once both types of males were observed within the same oyster.
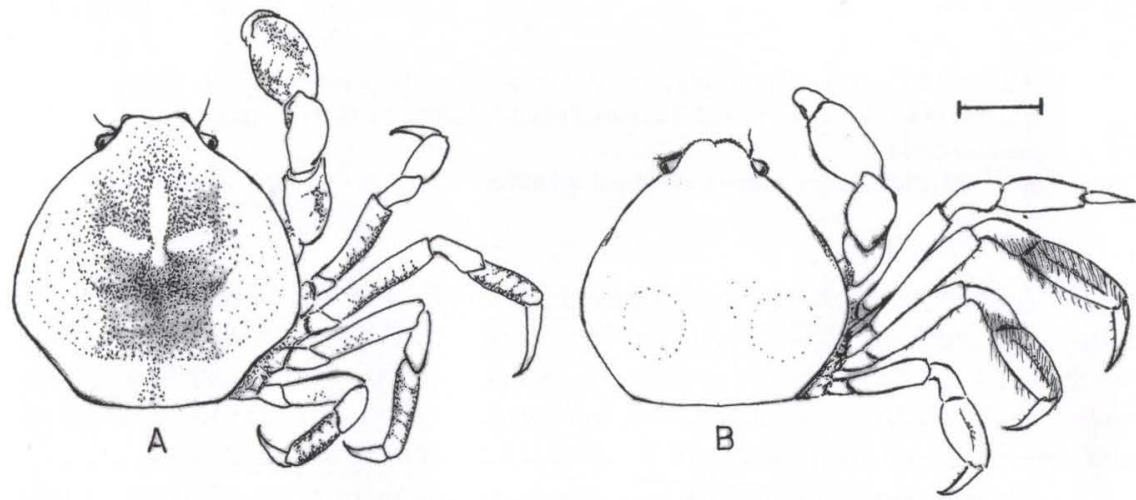

Fig. 1. Male specimens of Zaops ostreum. (A) Type A; (B) Type B.

ACKNOWLEDGEMENTS. The authors are grateful to Prof. Dr. Gustavo Augusto Schmidt de Melo of Museu de Zoologia, Universidade de São Paulo for confirming the identity of the species; to the CNPq for the award of fellowships during the tenure of which this study was carried out. The support received from PETROBRÁS to carry out this study is also gratefully acknowledged.

\section{REFERENCES}

MANNING, R.B. 1993. West African pinnotherid crabs, subfamily Pinnotherinae (Crustacea, Decapoda, Brachyura). Bull. Mus. Nat. Hist. Nat., Paris, (4) 15: 125-177.

Rathbun, M.J. 1918. The grapsoid crabs of America. Bull. U.S. Nat. Mus. 97: 1-461.

WilLIAMS, A.B. 1984. Shrimps, lobsters, and crabs of the Atlantic coast of the eastern United States,

Maine to Florida. Washington, D.C., Smithsonian Institution Press, 550p.

Recebido em 23.XI.2000; aceito em 22.X.2001. 